Preface

\title{
Traditional forest-related knowledge and sustainable forest management in Asia
}

\section{A R T I C L E I N F O}

Keywords:

Agroforestry

Forest history

Biodiversity conservation

Forest livelihoods

Indigenous knowledge

Local knowledge

Traditional forest-related knowledge (TFRK), most often tightly interwoven with traditional religious beliefs, customs, folklore, land-use practices and community-level decision-making processes, has sustained the cultures, livelihoods, and agricultural resource management systems of local and indigenous communities throughout Asia for centuries. Traditional knowledge systems in Asia, as in the rest of the world, have historically been dynamic, responding and adapting to changing environmental, social, economic and political conditions to ensure that forests and associated agricultural lands continue to provide tangible (foods, medicines, wood and other non-timber forest products, water and fertile soils) and intangible (spiritual, social and psychological health) benefits for present and future generations.

Despite their importance and contributions to sustainable rural livelihoods, traditional forest-related knowledge and practices are fast disappearing in most Asian countries, (and indeed worldwide) for a number of reasons. The expansion of the increasingly globalized market economies in previously self-sufficient rural areas, the negative impacts of some infrastructure, agriculture, tourism and other economic development interventions, greater exposure to mass media, and government policies and regulations within and outside of the forest sector restricting access and traditional use of forest resources, have led to a general erosion of traditional culture and of traditional land and forest management knowledge and practices throughout Asia, and declining interest in traditional wisdom, knowledge, and lifestyles among younger generations. The negative implications of this loss of traditional forest-related knowledge on livelihoods, cultural and biological diversity, as well as on the capacity of forested landscapes to provide environmental goods and services, remain poorly understood, largely unappreciated, and undervalued by policy-makers and the general public in most countries.

It was against this backdrop that the international conference "Sustainable Forest Management and Poverty Alleviation: Roles of Traditional Forest-related Knowledge" was convened in Kunming, Yunnan Province, China, in December 2007. The conference was jointly organized by the Chinese Academy of Forestry, the
International Union of Forest Research Organization's (IUFRO) Task Force on Traditional Forest Knowledge, and the Asia-Pacific Association of Forestry Research Institutions (APAFRI) with support from the Korea Forest Research Institute, the State Forest Administration of China, the Food and Agriculture Organization of the United Nations (FAO), the Austrian Federal Ministry of Agriculture, Forestry, Environment and Water Management and several other organizations in Asia. For the IUFRO Task Force on Traditional Forest Knowledge, this meeting was the third of a series of regional conferences being held in worldwide between 2006 and 2010. Selected papers from a previous conference in this series, (held in Florence in June 2006) were published in earlier special issue of this journal (Parrotta and Agnoletti, 2007).

The principal topics explored during the conference included:

- The contribution of traditional forest-related to achieving poverty reduction and related Millennium Development Goals;

- The roles of traditional knowledge and management practices in sustaining cultural identity and rural livelihoods;

- Application of traditional knowledge in management of forest and agricultural ecosystems for food, forest products and environmental services;

- Challenges and opportunities for the study, preservation and enhancement of traditional knowledge to contribute to sustainable rural livelihoods and sustainable use forest biodiversity under conditions of accelerating socioeconomic and environmental change;

- Policy issues and processes affecting the preservation and development of traditional forest-related knowledge.

The conference was attended by approximately 130 participants from 21 countries. They included researchers from various biophysical and social science disciplines, academicians and teachers, students, representatives from NGOs, governmental forestry agencies and intergovernmental organizations and bodies, as well as a significant representation of local and indigenous community members from China and several other Asian countries. A total of 65 papers and posters were presented on these topics during the conference covering a wide range of local case studies, historical analyses, and multi-site study syntheses. Extended abstracts of all presentations were published by IUFRO in the conference proceedings (Parrotta et al., 2008).

The diversity of scientific disciplines, cultural perspectives, backgrounds, experiences and philosophies of the conference participants fostered dynamic and thought-provoking discussions. Several topics and issues emerged that appear to be common to most regions and situations regarding the cultural, economic, and 
ecological importance of traditional forest-related knowledge, the challenges faced by local and indigenous communities to strengthen and preserve their traditional knowledge and lifestyles in the face of global change, pre-requisites for sustaining traditional forest management practices, and the appropriate role of formal forest science to assist in solving these issues.

In a large number of case studies presented, the rapid erosion of traditional forest-related knowledge was linked to social, economic, and governance trends arising both from within these communities and impinging on them from the broader society. These relate to the influence of expanding market economies, media influences on popular cultural values and lifestyle expectations, and land-use, transportation, economic and other policies that restrict opportunities for traditional forms of agricultural and forest management (traditional shifting cultivation, for example), undermine traditional communal decision-making institutions, and limit market access to forest products based on traditional practices. Lack of awareness among the general public, the media, and decisionmakers about the values (environmental, social, economic, cultural) of forests to local communities and the larger society that benefits from traditional forest management practices is widespread. Consequently, opportunities for involvement of local and indigenous communities in development of forest and land-use policies that directly affect their livelihoods are rare.

On the other hand, the Kunming conference highlighted a number of encouraging local and national examples and strategies for reversing these trends. Partnerships with NGOs, government forest agencies, universities and research organizations, business enterprises, and others have helped in some cases to preserve or restore traditional use rights and access for forest-dependent communities, yielded effective joint forest management arrangements, improved rural incomes by expanding marketing access for traditional forest products, and enhanced the profile and prestige of traditional forest-related knowledge within and outside of local and indigenous communities. The conference urged governments to mainstream traditional forest-related knowledge into sustainable forest management and poverty alleviation development strategies, policies, and legislative agendas.

The current and potential importance of forest science to helping protect and realize the full potential of traditional forest-related knowledge was given considerable attention during the Kunming conference. Among the major points echoed throughout the meeting by participants were the importance of multi-disciplinary, participatory, research (both biophysical and social sciences); the critical issue of trust and respect (for communities, their cultures, beliefs and practices) in research on traditional knowledge, and the need for such research to help solve immediate, practical problems faced by the communities in which they work.

Working with local and indigenous communities, the forest science community can contribute to the revitalization of traditional forest-related knowledge in several important ways, including:

- Documentation of TFRK in close partnership with holders and users of this knowledge, using ethically appropriate study methods;

- Research on traditional forest management conservation and practices that help to elucidate and generalize the ecological underpinnings of traditional knowledge;

- Economics, marketing and policy research aimed at improving opportunities for increasing rural incomes from products and services provided by application of TFRK;

- Integration of TFK into forestry curricula, and partnership with the holders and users of traditional knowledge for education of the general public and decision-makers on the livelihood and environmental values of TFRK.
In this volume, we have selected papers from the Kunming conference that focus on these and other key topics related to traditional forest-related knowledge in Asia, its historical and current utilization by local and indigenous communities to sustain livelihoods, cultural traditions and conserve biodiversity, and innovative approaches to integrating traditional and formal (scientific) forest-related knowledge for sustainable management of forested landscapes in a changing world. These include studies from China, Korea, the Philippines, Indonesia, Malaysia, Thailand, India and Nepal.

We hope that this special issue of Forest Ecology and Management will provide new perspectives on the historical and present-day role of traditional forest-related knowledge in the sustainable management of forests and associated agroecosystems in Asia; foster a greater appreciation of and respect for the knowledge and wisdom that is part of the cultural traditions and practices of local and indigenous communities of the region; and encourage increased multidisciplinary research and collaboration (participatory research) in traditional communities to explore the sometimes obscure common ground traditional knowledge systems and formal (scientific) knowledge as a basis for utilizing the best of both to meet the growing environmental, social and economic challenges facing rural communities with respect to the management and conservation of forested landscapes in Asia.

In closing, we wish to thank all authors who submitted papers for consideration for publication in this volume. We also acknowledge the invaluable assistance of all those who served as peer reviewers and contributed greatly to the relevance and quality of this special issue: Susan J. Alexander, Donald Baker, Gary Bull, Ram P. Chaudhary, Stephen Elliott, Alan Hamilton, Robin Kimmerer, Jino Kwon, Luohui Liang, Shin Nagata, K.K.N. Nair, Matti Palo, Carlos Perez, Joshua L. Posner, Sunil Puri, Kanok Rerkasem, Pei Shengji, Eklabya Sharma, Chusie Trisonthi, Xu Jianchu, Xu Jintao, and Xue Dayuan.

\section{References}

Parrotta, J.A., Liu, J., \& Sim, H-C., 2008. Sustainable Forest Management and Poverty Alleviation: Roles of Traditional Forest-related Knowledge. IUFRO World Series Vol. 21. Vienna, Austria: International Union of Forest Research Organizations, 224 pp.

Parrotta, J.A., Agnoletti, M., 2007. Traditional Knowledge, Cultural Heritage and Sustainable Forest Management. Forest Ecology and Management 249, $1-139$.

John A. Parrotta ${ }^{\mathrm{a}, *}$, Lim Hin Fui ${ }^{\mathrm{b}}$, Liu Jinlong ${ }^{\mathrm{c}}$, P.S. Ramakrishnan ${ }^{d}$, Youn Yeo-Chang ${ }^{\mathrm{e}}$

aIUFRO Task Force on Traditional Forest Knowledge, U.S. Forest Service, Research and Development, 4th floor - RP-C, 1601 North Kent Street, Arlington VA 22209, USA

${ }^{\mathrm{b}}$ Forest Research Institute Malaysia, Kepong, 52109 Kuala Lumpur, Malaysia

'School of Agricultural Economics and Rural Development, Renmin University of China, Beijing, 100872, China

${ }^{\mathrm{d} S c h o o l ~ o f ~ E n v i r o n m e n t a l ~ S c i e n c e s, ~ J a w a h a r l a l ~ N e h r u ~ U n i v e r s i t y, ~}$ New Delhi - 110167, India

eDepartment of Forest Sciences, Seoul National University, San 56-1, Sillim-dong, Gwanak-gu, Seoul 151-742,

Republic of Korea

${ }^{*}$ Corresponding author.

Tel.: +1 703 6054178; fax: +1 7036055131

E-mail address: jparrotta@fs.fed.us 